Article

\title{
Utilisation of Mass and Night Ventilation in Decreasing Cooling Load Demand
}

\author{
Michael Darmanis ${ }^{1,2, *}$, Murat Çakan ${ }^{1}$, Konstantinos P. Moustris ${ }^{2} \oplus$, Kosmas A. Kavadias ${ }^{3}$ \\ and Konstantinos-Stefanos P. Nikas ${ }^{2,4}$ (D) \\ 1 Faculty of Mechanical Engineering, Istanbul Technical University, Beyoğlu, Istanbul 34437, Turkey; \\ cakanmu@itu.edu.tr \\ 2 Laboratory of Fluid Mechanics, Department of Mechanical Engineering, University of West Attica, \\ GR12244 Athens, Greece; kmoustris@uniwa.gr (K.P.M.); ksnikas@uniwa.gr (K.-S.P.N.) \\ 3 Laboratory of Soft Energy Applications \& Environmental Protection, Department of Mechanical \\ Engineering, University of West Attica, GR12244 Athens, Greece; kkav@uniwa.gr \\ 4 Laboratory of Heat Transfer, Department of Mechanical Engineering, University of West Attica, \\ GR12244 Athens, Greece \\ * Correspondence: michaledarm@gmail.com; Tel.: +30-697-809-1358
}

Received: 15 July 2020; Accepted: 15 September 2020; Published: 22 September 2020

\begin{abstract}
The building sector consumes 36\% of the world's energy and produces around $40 \%$ of energy-related carbon emissions. While the building industry moves towards a zero net greenhouse-gas emission policy, ventilation is, and will be, a necessity for the preservation of air quality-especially in climates defined by unsavoury conditions. Therefore, a "mixing mode" cooling system was employed to lower the required energy consumption at an earthen building situated in the premises of Istanbul Technical University. A room of the high-mass earthen building was monitored under different ventilation and shading conditions. Night ventilation was conducted using two modes, 3.2 and 2.3 air changes per hour, and the air conditioning unit, operating from 08:00 to $17: 00$, had a set temperature of $23^{\circ} \mathrm{C}$. Night ventilation was somewhat impactful, reducing the average expected cooling energy demand up to $27 \%$. Furthermore, the earthen building proved to be extremely effective on moderating extremes of temperature under non-ventilated conditions. During a rather hot day, with an outdoor maximum temperature of $35^{\circ} \mathrm{C}$, the indoor maximum temperature of the high-mass building was only $25^{\circ} \mathrm{C}$, namely within thermal comfort levels. The diurnal temperature proved to be key in the effective application of night ventilation.
\end{abstract}

Keywords: cooling demand; cooling systems; earthen materials; mixed-mode cooling systems; night ventilation; passive cooling-techniques; thermal comfort

\section{Introduction}

Passive cooling systems have been, and still are, the subject of intensive investigation. Their main interest lies in the significant improvement of thermal comfort they can induce while minimising energy costs. The term "passive" is used in the same sense as in Givoni's exposition of passive cooling strategies [1]; that is, the emphasis in utilising natural cooling resources for the rejection of heat from a building, and in the special case of collaboration of cooling systems, that the heat transfer system is efficient and low-cost.

One (of the several) passive and low-energy cooling system(s) is the cooling of the structural mass by ventilation during the night, namely, nocturnal convective cooling; other means of passive cooling methods include (i) comfort ventilation, (ii) nocturnal radiant cooling, (iii) indirect evaporative cooling, and (iv) utilization of the soil as a cooling source [1,2]. 
In this work, nocturnal convective cooling will be the subject of main interest, and shall henceforth be referred to as night ventilation. Buildings ventilated at night experience a continuous cooling, by convection, of their structural mass. The following day, this cooled mass may serve as a heat tank to absorb, by natural convection and radiation, the heat penetrating into and generated inside these buildings [1]. When coupled with an air-conditioning unit, this heat dissipation may (and often can) result in energy conservation and reduce summer peak demand for electricity.

Such couplings, also known as "mixed mode" cooling systems [2], have also been suggested by Givoni [1]. Collaborations of this kind are particularly attractive for the special case of combining night ventilation and mechanical cooling, as the latter requires high airflow rates. Thus, night ventilation does not further burden the construction's initial cost, as stated by Blondeau et al. [3].

Night ventilation can be applied to all types of buildings, provided that they are well-insulated and their interior mass enables sufficient cooling potential. Low-mass buildings, however, even when ventilated at night, tend not to retain enough cool reserve to significantly reduce the rate of temperature rise during the daytime, and may actually act as heat traps $[4,5]$.

Efficiency of night ventilation, in decreasing cooling energy demand and making for improved indoor conditions for occupants, rests upon three main considerations [1,6-8]: the climatic parameters, such as diurnal temperature range, relative humidity, and topography; building parameters, such as useful thermal inertia and functionality; and last but not least, technical parameters, such as optimal operation, operation time, air flow rates, and control techniques.

Adopting passive and low-energy cooling systems has become a pressing subject. This is a direct consequence of the desire to conserve energy and to reduce summer peak demand for electricity caused by air-conditioning. However, there is also the pollution argument to consider. In 2015, at a meeting in Paris, world leaders pledged to move towards a zero net greenhouse gas emission policy. This is a challenging task, and the building industry makes it even more so. Buildings consume $36 \%$ of the world's energy and produce around $40 \%$ of energy-related carbon emissions. Cement manufacturing contributes $6 \%$ to the world's carbon emissions. Steel, a large quantity of which goes into buildings, accounts for another $8 \%$ [9].

More recycled steel and reduction of lorry journeys, by prefabrication in off-site factories, may make buildings "greener". However, no other building material has environmental credentials as exciting and overlooked as adobe. Adobes are dried mud or unburnt bricks that have been used in the construction of dwellings and other structures for thousands of years, and bear a near-zero carbon footprint [10]. The term is usually used to refer to various building materials whose base is either mud or soil [11].

The defining property of adobe (or earthen) buildings lies in their unique ability to store cooling loads. They are known to reduce cooling demand during hot summers due to the thermal inertial effect that they may induce [12]. The outdoor temperature both rises above and falls below the indoor temperature. The same, however, is not true for the winter season. During cold winters, the indoor temperature always remains above the outdoor temperature, therefore increasing heat demand.

The present study deals with the collaboration of mass and night ventilation as a way to improve comfort or reduce the cooling loads of an earthen building in summer. It first presents the main results of the full-fledged experiment, the aim of which was to check the effectiveness of night ventilation by noting the decrease of cooling energy. The impact of the environment's diurnal temperature and the air flow rate of night ventilation are discussed. Then, the structure's natural behaviour is assessed by monitoring it without the use of any cooling applications.

Before moving forward, some of the published contributions that bear directly on the effectiveness of similar cooling systems need to be discussed. Numerous studies, both numeric and experimental in nature, have demonstrated the ability of night ventilation to improve comfort conditions [5,7,13-15]. Shaviv et al. [5] argued that significant comfort conditions could be achieved with up to 20 air changes per hour, while Agas et al. [13] and Blondeau et al. [7] could not indicate any significant comfort improvement above 8 ach to 10 ach. 
Blondeau et al. [3] experimented in a high-mass building, whose fabric was made of concrete, and showed that night ventilation decreased as the required indoor temperature increased. For night ventilation intensity of $8 \mathrm{ach}$, the calculated mechanical energy reduction varied from $12 \%$ to $56 \%$ for an air-conditioning set point of $22^{\circ} \mathrm{C}$ to $26^{\circ} \mathrm{C}$; whereas Geros et al. [14], working with a light-mass structure made of concrete, showed that for a $28^{\circ} \mathrm{C}$ set point, the calculated conservation varied from $14 \%$ to $36 \%$ for 5 ach to 30 ach. It was also estimated that 30 ach could reduce the cooling load demand by up to $71 \%$. A large-scale experiment on residential buildings (covering a vast spectrum of cooling needs and applied flow rates) was conducted by Santamouris et al. [4]. Energy savings, with an average of $12 \mathrm{~kW} \mathrm{~h} \mathrm{~m}^{-2} \mathrm{y}^{-1}$, could be achieved with the use of night cooling. On a different note, Shaviv et al. [5] and Givoni [16] showed that night ventilation had only a very small effect on the indoor maxima of low-mass buildings. Particularly, the former pointed out that light structures had the tendency to behave like heat traps; in many instances, the indoor maxima was higher than the outdoor one.

\section{Materials and Methods}

\subsection{Full-Fledged Experiment}

The earthen building (see Figure 1a on page 3), situated at ITU Ayazaga Kampusu, Istanbul $\left(41^{\circ} 6^{\prime} 2^{\prime \prime} \mathrm{N} 29^{\circ} 1^{\prime} 16^{\prime \prime} \mathrm{E}\right)$ is made of alker, a mud-based building material [17], often designated as stabilized adobe. It bears a density $(\rho)$ of $1620 \mathrm{~kg} \mathrm{~m}^{-3}$ and a specific heat capacity $\left(C_{p}\right)$ of $1.2 \mathrm{~kJ} \mathrm{~kg}^{-1} \mathrm{~K}^{-1}$. Conductivity measurements conducted by Kafescioğlu [18] yielded an R-value of approximately $2 \mathrm{~m}^{2} \mathrm{~K} \mathrm{~W}^{-1}$ and a thermal conductivity $(\lambda)$ of $0.5 \mathrm{~W} \mathrm{~m}^{-1} \mathrm{~K}^{-1}$. Alker is an improved version of adobe. It's significantly tougher, more resilient to water, and less susceptible to cracking. Stabilized adobe bricks contain enough stabilizer (in this case, $2.5 \%$ to $5 \%$ of slaked lime) so as to limit water absorption of the brick.

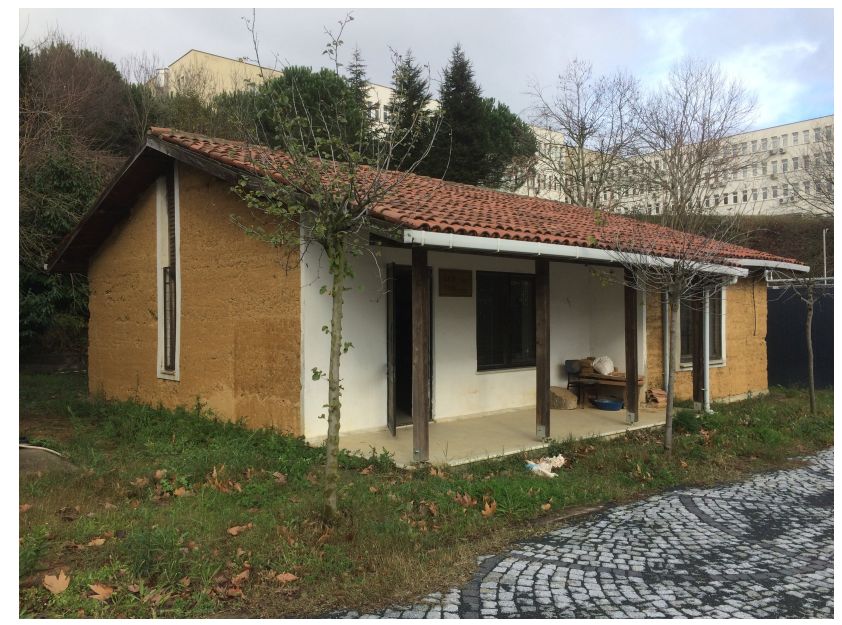

(a)

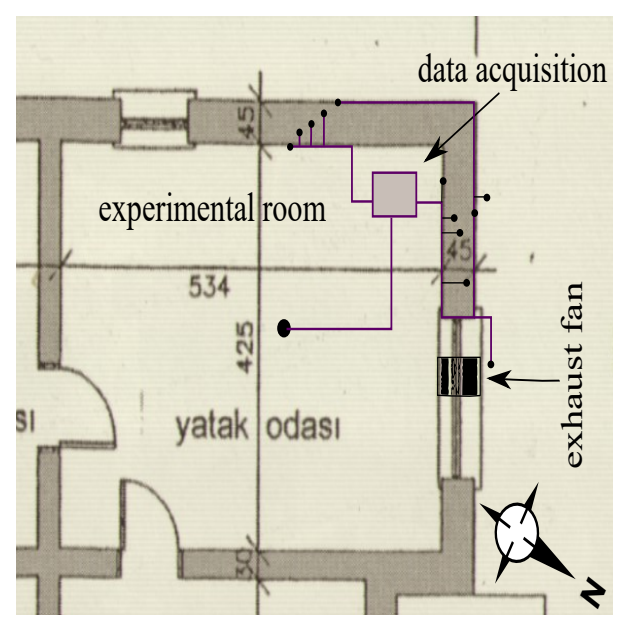

(b)

Figure 1. Earthen building. (a) Side view, (b) room plan [18].

The interior walls of the building had a width of $30 \mathrm{~cm}$ and the outer walls were $45 \mathrm{~cm}$ thick, while their inner surface was covered with normal gypsum plaster. The night ventilated zone composed of a room with two windows (one in each wall) and a volume of $44.93 \mathrm{~m}^{3}$. The doorways of the two walls, adjacent to the room under investigation, were blocked using a plastic cloth and house furniture. The directions of the walls in contact with the environment were $154^{\circ}$ south-east and $59^{\circ}$ north-east, respectively.

To perform night ventilation, a fan was installed in the northeastern window (see Figure $1 \mathrm{~b}$ on page 3 ) of the building, with the windows of the experimental room being 
shut. Using a set point of $23^{\circ} \mathrm{C}$, the air conditioning unit (of approximately $7000 \mathrm{BTU}$ ) operated from 08:00 until 17:00 on a daily basis.

A total of 13 thermocouples were used for the measurements of (i) the air temperature of the room and of the environment, (ii) the operating temperature of the fan during night ventilation, and (iii) five measurements across the building's blocks for each of the two external walls, respectively. All the thermocouples were made from the same metallurgical batch of K-type (Chromel-Alumel) thermocouple wire, and were TIG welded in-house. A computer-based data acquisition system (Keithley 2700) was employed to acquire the thermocouples' output. Adequate adhesion of the sensors with the walls' surfaces was ensured through the use of duck tape, thus preventing thermal bridging. For the indoor temperature, a thermocouple was welded upon a metal mass (approximately $50 \mathrm{~g}$ ) located at the center of the room.

The time interval between two measurements was $15 \mathrm{~min}$, and the average absolute error according to the manufacturer was $0.5^{\circ} \mathrm{C}$. However, a reliability test showed that all the thermocouples were giving the same temperature within an uncertainty of $0.4^{\circ} \mathrm{C}$. A power meter was used to measure the electricity consumption of the air-conditioning unit.

In its normal configuration, the maximum air flow given by the fan manufacturer was $140 \mathrm{~m}^{3} \mathrm{~h}^{-1}$, roughly equivalent to $3 \mathrm{ach}$. This value was then verified by airspeed measurements using an anemometer (Testo Term type 4500/4510). Measurements of the air flow rate with each fan speed were performed. The average air speed in front of the fan (from the inside) was measured at six points, twice. The two measurements of each point were then combined as weighted averages (see Taylor [19]). Thus, each outlet speed is the average of six measurements at each speed. The air flow rate and the air changes per hour were calculated by taking into account the area of the fan's opening. At medium speed $\left(4.7 \mathrm{~m} \mathrm{~s}^{-1}\right)$, the fan yielded 2.3 air changes per hour, while at full speed $\left(6.7 \mathrm{~m} \mathrm{~s}^{-1}\right)$, there were 3.2 air changes per hour.

Several schemes were monitored in order to assess the thermal behaviour of the building. The following operating conditions were employed at a sequence of experiments, spanning a total of 24 days.

- Windows unshaded, no night ventilation, and AC operation;

- Windows unshaded, full-power night ventilation (i.e., $3.2 \mathrm{ach}$ ), and AC operation;

- Windows unshaded, half-power night ventilation (i.e., 2.3 ach), and AC operation;

- Windows shaded, no night ventilation, and no AC operation.

Night ventilation was employed between 21:00 and 08:00 (local times), no sooner than when the outside air was sufficiently lower $\left(2^{\circ} \mathrm{C}\right.$ to $\left.3^{\circ} \mathrm{C}\right)$ than that inside.

\subsection{Data Analysis}

Out of 13 temperature measurements received, only three will be assessed in the present work-namely, the outdoor, indoor, and fan (when needed) temperatures.

\subsubsection{Uncertainty Analysis}

The measurement uncertainties based on a 95\% confidence level are listed in Table 1 on page 5 . All errors are expressed as the percentage of their corresponding values. The root-sum-square method, as defined by Kline and McClintock [20], was used. 
Table 1. Measured quantities, their typical values, and their uncertainties.

\begin{tabular}{lcc}
\hline Quantity & Typical Value & Measurement Error \\
\hline $\begin{array}{l}\text { Fan diameter, } \\
D(\mathrm{~mm})\end{array}$ & 114 & $\pm 1.75 \%$ \\
$\begin{array}{l}\text { Fan gap thickness, } \\
h(\mathrm{~mm})\end{array}$ & 20 & $\pm 5.00 \%$ \\
$\begin{array}{l}\text { Fan air speed, } \\
u\left(\mathrm{~m} \mathrm{~s}^{-1}\right)\end{array}$ & 6.7 & $\pm 4.26 \%$ \\
$\begin{array}{l}\text { Temperature, } \\
T\left({ }^{\circ} \mathrm{C}\right)\end{array}$ & 30 & $\pm 1.33 \%$ \\
$\begin{array}{l}\text { Energy consumption, } \\
Q_{A C}(\mathrm{kWh})\end{array}$ & 1.2 & $\pm 2.94 \%$ \\
\hline
\end{tabular}

The surface of the fan, assuming a production tolerance, gave an uncertainty of $7.23 \%$, and combined with the air speed's uncertainty, yielded an accuracy of $8.35 \%$ for the air changes per hour.

\subsubsection{Raw Data Filtering}

Since in this work, the data were not intended for a complex analysis (or for direct calculations), and will exclusively be called upon in an observatory kind of fashion, the removal of high-frequency components alone was deemed to suffice for the dataset's quality control.

Following this premise, to track temperature data more closely and to account for transient effects, the Savitzky-Golay filter (see Orfanidis [21]), also known as the smoothing polynomial filter, was used in the MATLAB environment [22] (pp. 329-344). The filter has a tendency to preserve the dominant frequency components of the data while smoothing it. Undesirable effects, such as noise due to sampling inaccuracies, will thus be avoided. An example of the filter's application can be seen in Figure 2 on page 5.

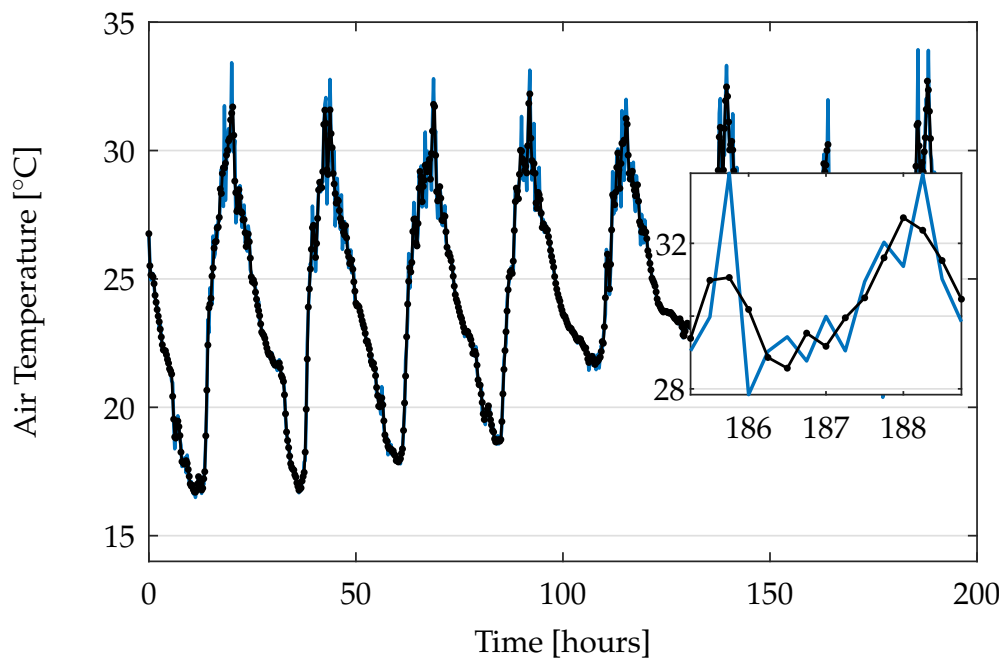

$\longrightarrow$ Raw data $\longrightarrow$ Filtered data

Figure 2. Raw and filtered temperature data. 


\section{Results and Discussion}

As the main interest in this study was the effectiveness of night ventilation in providing for a low-cost way to cool structures, the main criterion chosen for evaluating the performance of the experiment was the decrease of cooling energy.

\subsection{Mechanical Cooling Supplemented by Night Ventilation}

In the first phase, the windows were unshaded. An air-conditioning unit was working throughout the period. Figure 3 on page 6 shows the daily indoor and outdoor temperature patterns of the building. During the first half, with no fan-temperature readings, only the air-conditioning unit operated as a cooling agent. Then, full-capacity night ventilation followed. The gap in the dataset, as indicated in the graph, was due to a power outage.

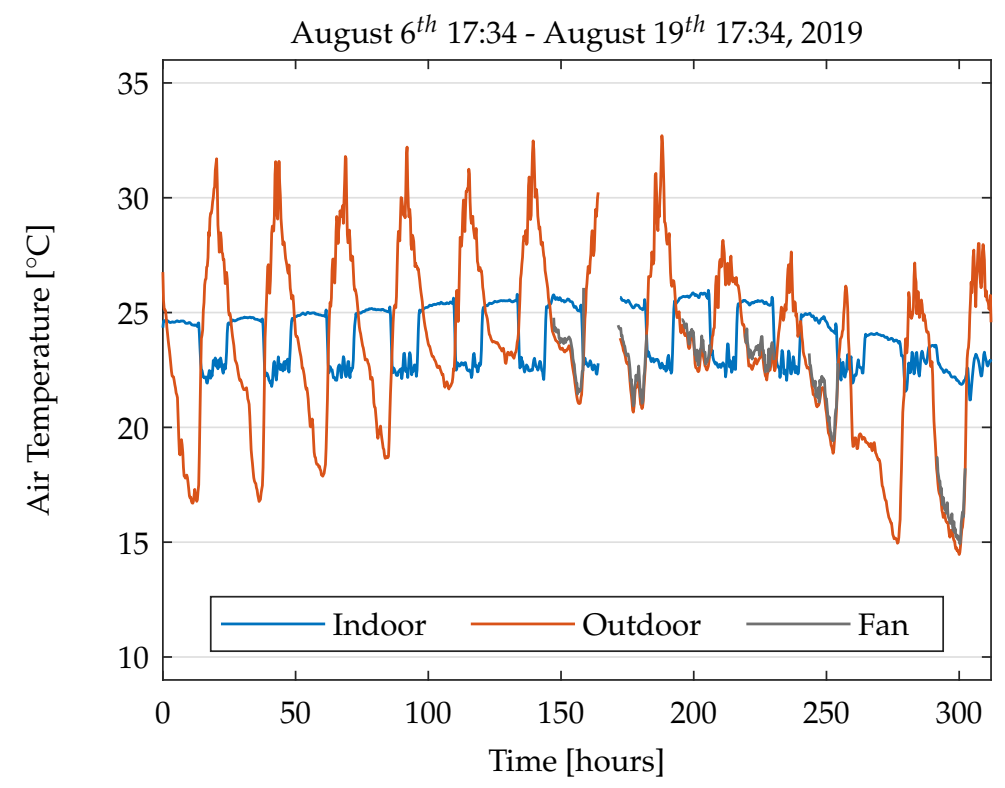

Figure 3. Daily outdoor and indoor temperature patterns of the building, with a working air-conditioning unit and unshaded windows, for two periods: first without, and then with full-capacity night ventilation.

This period was characterised by mild fluctuations of the outdoor average and diurnal temperatures, although near the end, rainy and windy days occurred. Seeing that the diurnal temperature was rather high for the non-ventilated part was rather unfortunate. Diurnal temperature, and high values of minima, constitute an efficient indicator for successfully corroborating night ventilation with mechanical cooling means, as previously mentioned.

After the first phase finished, the building was left to float freely for about 10 days, so as to alleviate any inertial effect superseding passive cooling. Consecutively, night ventilation was re-employed for a three-day period. The setup was the same, the only difference being that the night ventilation operated at half-capacity. As Figure 4 on page 7 shows, weather fluctuations scarcely occurred, but yet again, small diurnal temperatures and high minima values prevailed. 


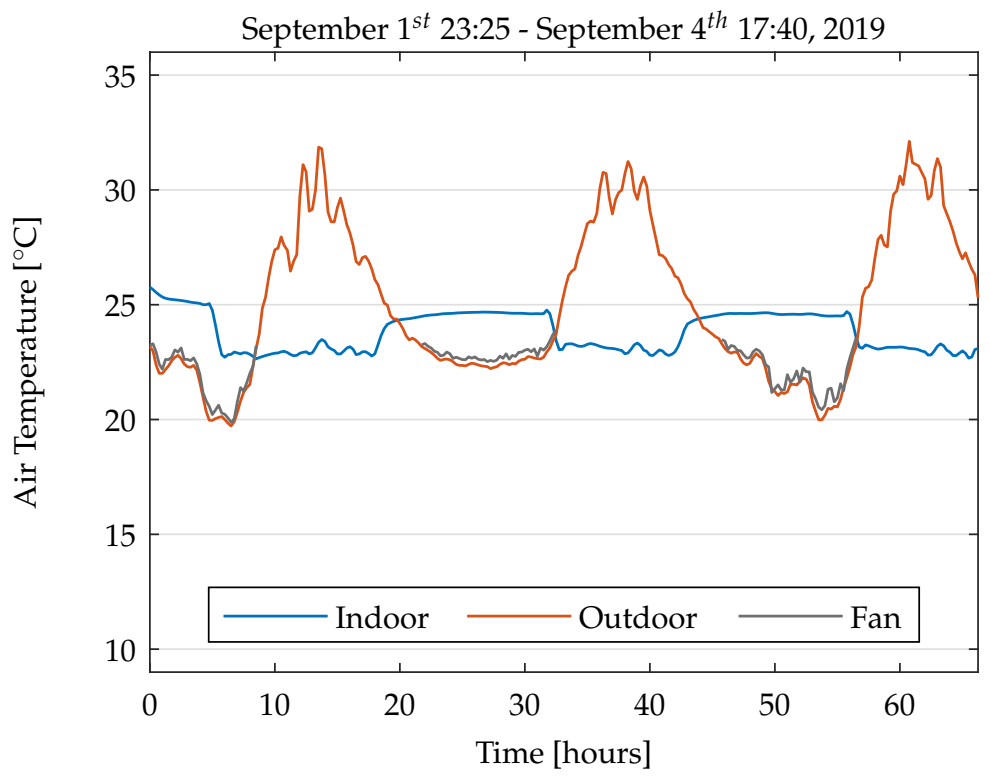

Figure 4. Daily outdoor and indoor temperature patterns of the building with a working air-conditioning unit, unshaded windows, and half-capacity night ventilation.

Figure 5 on page 7 shows the outdoor minimum, maximum, and average temperature for every day monitored, as well as the daily corresponding power consumption of the air-conditioning unit. A drop of the average cooling energy consumption, when night ventilation was at full capacity, below the non-night-ventilated period of about $27 \%$ per day was observed. At half-capacity, night ventilation yielded a drop of mechanical-energy-consumption below the non-night-ventilated period of about $15 \%$ per day.

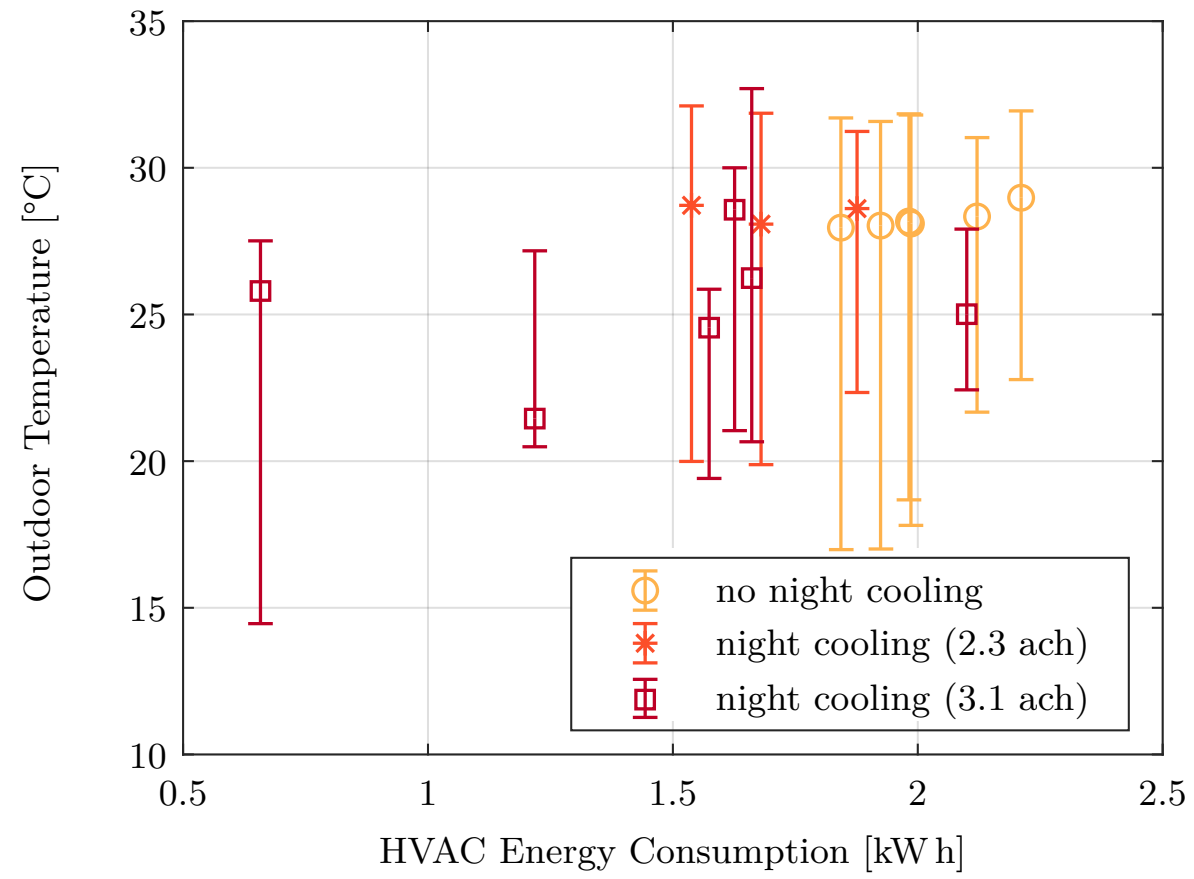

Figure 5. Cooling energy evaluation of night ventilation with respect to the daily average and diurnal temperatures.

However, to speak bluntly, the comparison of the average daily energy consumption between different days seems to be a fallacious one. Indeed, each single day is a very complex system, 
exhibiting strong multi-dimensional behaviour, and it would make little sense to assume similarities. However, considering the outdoor temperature as the dominant comparison factor, in this case, one may assume that non-night-ventilated days required less cooling. Apart from the average outdoor temperatures being somewhat similar in both non-night-ventilated and night-ventilated days, the highest diurnal temperature values lay within the former. Thus, one would expect that the night-ventilated days would be in need of more cooling. The fact that the average cooling consumption was less testifies to the possible contribution of night ventilation in reducing cooling demand.

An interesting observation is that when night ventilation is employed in days with low diurnal temperature and minima above $20^{\circ} \mathrm{C}$, the energy consumption is similar to the values of non-night-ventilated days. As stated by other authors $[4,5,16]$, night ventilation ought to be used with sufficient diurnal range and minima well below $20^{\circ} \mathrm{C}$, otherwise the structure acts as a heat trap, and may even reach higher minima values than that outside.

The two unexpectedly low energy values of the graph (i.e., $1.22 \mathrm{kWh}$ and $0.66 \mathrm{kWh}$ ) succeeded a rainy night. Even during a rather hot summer, a rainy day can store enough cooling loads due to outer surface evaporation, and significantly reduce the cooling load demand of the proceeding day(s). In a similar fashion, a sunny day during cold winter helps with the required heating loads.

It would seem that night ventilation intensity is invariant of cooling demand reduction. Indeed, as previously stated, numerous studies $[5,7,13]$ have shown that in order to achieve notable results, night ventilation ought to be employed at, 10 ach, at the very least. Nevertheless, the fact that cooling demand was somewhat decreased may be (and most likely is) attributed to the unusually high thermal mass of the structure, and its material's unique thermal properties.

\subsection{Free-Floating Structure}

In the second phase, the windows were provided with fixed, rolling, internal shades. The internal shades were black in color, made by a thermal insulated fabric with $100 \%$ blackout UV protection. No form of cooling was used. Figure 6 shows the daily indoor/outdoor, as well as the inner/outer surface temperature patterns of the shaded room.

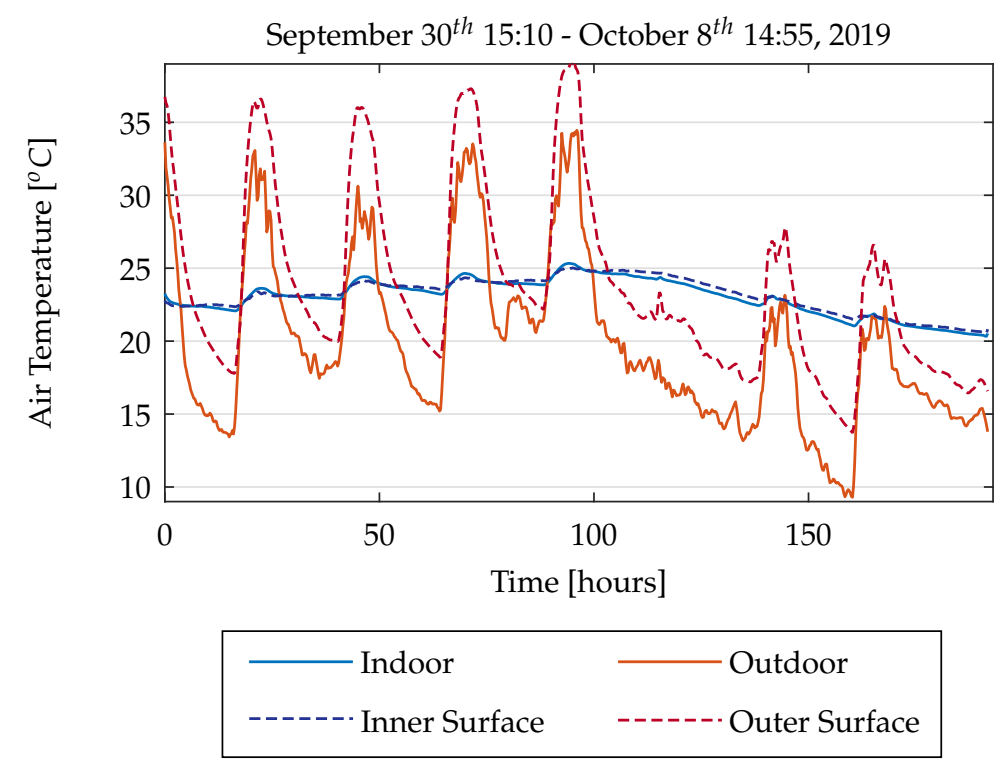

Figure 6. Daily indoor/outdoor and inner/outer surface temperature patterns of the building. The windows were shaded, and no cooling method (passive or mechanical) was employed.

The high-time lag (about 3 to $4 \mathrm{~h}$ ) recorded testifies to the thermal stability that the building can provide. This observation is in agreement with the corresponding literature on earthen materials. Aimilios et al. [12] showed that a wall $50 \mathrm{~cm}$ thick yielded a time lag of approximately $5 \mathrm{~h}$, while Baggs 
and Mortensen [23] suggested that a $25 \mathrm{~cm}$ wall presented a time lag of $9.2 \mathrm{~h}$. Both Asan [24] and Andreadaki [25] indicated a time lag of about $8 \mathrm{~h}$ for a $30 \mathrm{~cm}$ wall.

The beginning of the monitoring period was characterised by mild fluctuations of the outdoor average and diurnal temperatures, while the rest was defined by steep changes due to unsavoury weather conditions. Note that the indoor temperature, although of similar pattern to that outdoors, is strictly contained within the bounds of $20^{\circ} \mathrm{C}$ to $25^{\circ} \mathrm{C}$.

A drop of the indoor maximum below the outdoor maximum of about $26 \%$ can be noticed at the $95 \mathrm{~h}$ mark. The indoor minimum temperature was also higher than the outdoor minimum by about $133 \%$ at the $160 \mathrm{~h}$ mark. The typical indoor temperature swing of the building was about $13 \%$ of the outdoor range. These data are in total agreement with Givoni's [1] observation of how a high-mass structure ought to behave while well-insulated and shaded.

Figure 7 on page 9 shows the cumulative density distribution of the same period. An increase of the indoor average mean temperature over the outdoor average mean of about $28 \%$ can readily be observed. This comes to show that adobe buildings can not only minimise heat stress during heat waves, but also maximise thermal comfort during cold waves.

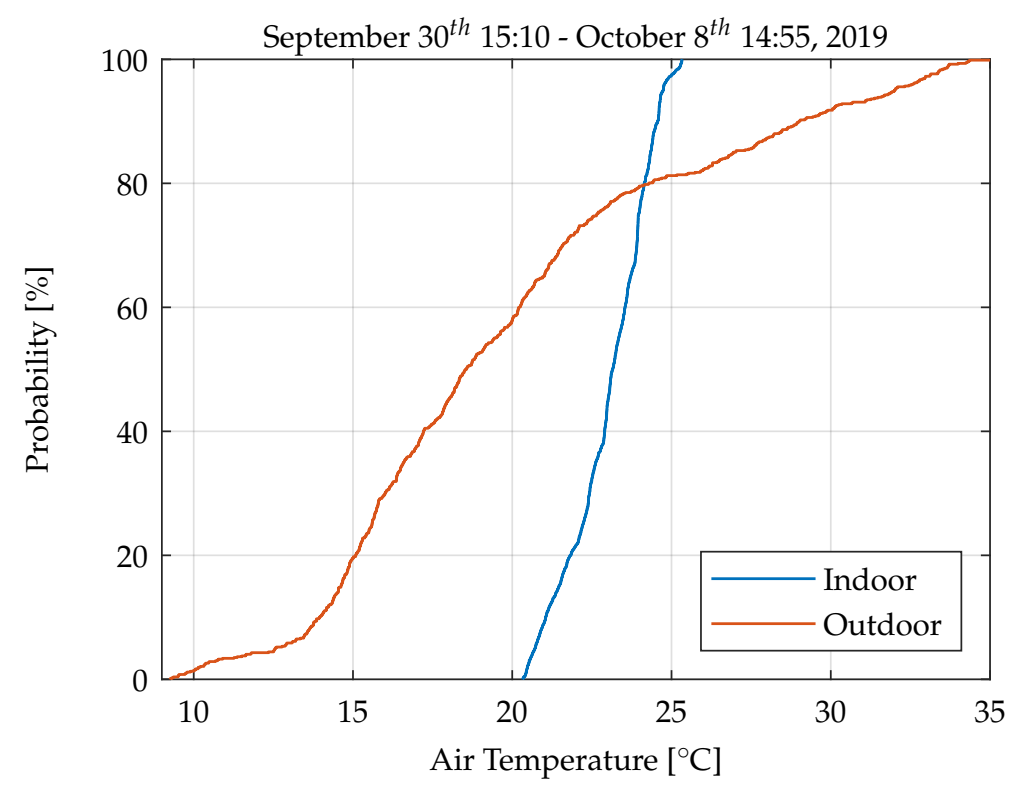

Figure 7. Cumulative frequency distribution of Figure 6 on page 8.

\section{Conclusions}

In this work, the collaboration of mass and night ventilation in decreasing cooling demand was experimentally investigated during the late summer period of 2019. In order to correctly estimate and control the airflow during night ventilation, an exhaust fan was used.

Both schemes where mechanical cooling was corroborated by night ventilation showed real promise. The average daily energy consumption decrease achieved varied from $15 \%$ to $27 \%$. However, no clear correlation between night ventilation intensity and energy-saving could be established.

The building itself, when free-floating, maintained acceptable thermal comfort levels during unsavoury weather conditions. Its high thermal mass lowered the indoor maxima during a heat period and increased it for a cold period. Due to the inertial effect introduced by the structural material, the average indoor temperature swing was also $13 \%$ of the outdoor swing.

Night ventilation could be a good cooling strategy in regions where the diurnal temperature range is high enough to enable significant cooling storage, thereby lowering the need for mechanical cooling. Further, and more robust research is required to fully realise the building's potential for night ventilation. 
Application of passive cooling systems alone will not bring the environmental cost of the world's buildings into line. However, "mixing mode" cooling systems may make the buildings' greenhouse gas policy more feasible, expanding the discourse from passive and mechanical cooling systems to an integrated variant of the two.

Author Contributions: Conceptualisation, M.Ç. and M.D.; methodology, M.Ç. and M.D.; software, M.D.; validation, M.D., M.Ç. and K.P.M.; formal analysis, M.D. and K.A.K.; investigation, M.D., M.Ç. and K.P.M.; resources, M.Ç. and M.D.; data curation, M.D.; writing-original draft preparation, M.D.; writing-review and editing, M.D., K.P.M., K.A.K. and K.-S.P.N.; visualization, M.D.; supervision, M.Ç.; project administration, M.Ç. and M.D. All authors have read and agreed to the published version of the manuscript.

Funding: This research received no external funding.

Acknowledgments: We are grateful to Ruhi Kafescioğlu for providing access to the adobe house, for otherwise the experiment would not have been possible. We are also extremely grateful to Duru Koçak, whose help with setting up the experimental equipment saved us innumerable hours of labour.

Conflicts of Interest: The authors declare no conflict of interest.

\section{References}

1. Givoni, B. Performance and applicability of passive and low-energy cooling systems. Energy Build. 1991, 17, 177-199. [CrossRef]

2. Liddament, M.W. A Guide to Energy Efficient Ventilation; Air Infiltration and Ventilation Centre: Coverty, UK, 1996; pp. 135-145.

3. Blondeau, P.; Spérandio, M.; Allard, F. Night ventilation for building cooling in summer. Sol. Energy 1997, 61, 327-335. [CrossRef]

4. Santamouris, M.; Sfakianaki, A.; Pavlou, K. On the efficiency of night ventilation techniques applied to residential buildings. Energy Build. 2010, 42, 1309-1313. [CrossRef]

5. Shaviv, E.; Yezioro, A.; Capeluto, I.G. Thermal mass and night ventilation as passive cooling design strategy. Renew. Energy 2001, 24, 445-452. [CrossRef]

6. Givoni, B. Comfort, climate analysis and building design guidelines. Energy Build. 1992, 18, 11-23. [CrossRef]

7. Blondeau, P.; Sperandio, M.; Sandu, L. Potentialites de la ventilation nocturne pour le refraichissement des batiments du Sud de l'Europe. In Proceedings of the European Conference Energy Performance and Indoor Climate in Buildings, Lyon, France, 24-26 November 1994; G. Guarracino, Ecole Nationale des Travaux Publics de l'Etat: Lyon, France, 1994; Volume 3, pp. 854-859.

8. Solgi, E.; Hamedani, Z.; Fernando, R.; Skates, H.; Orji, N.E. A literature review of night ventilation strategies in buildings. Energy Build. 2018, 173, 337-352. [CrossRef]

9. Sbci, U. Buildings and Climate Change: Summary for Decision-Makers; United Nations Environmental Programme, Sustainable Buildings and Climate Initiative: Paris, France, 2009; pp. 1-62.

10. Olukoya Obafemi, A.P.; Kurt, S. Environmental impacts of adobe as a building material: The north cyprus traditional building case. Case Stud. Constr. Mater. 2016, 4, 32-41. [CrossRef]

11. Austin, G.S. Adobe As a Building Material. N. M. Geol. 1984, 6, 69-71.

12. Aimilios, M.; Philokyprou, M.; Thravalou, S.; Ioannou, I. The role of adobes in the thermal performance of vernacular dwellings. In Proceedings of the Terra Conference, Lyon, France, 11-14 July 2016; pp. 1-7.

13. Agas, G.; Matsaggos, T.; Santamouris, M.; Argyriou, A. On the use of the atmospheric heat sinks for heat dissipation. Energy Build. 1991, 17, 321-329. [CrossRef]

14. Geros, V.; Santamouris, M.; Tsangrasoulis, A.; Guarracino, G. Experimental evaluation of night ventilation phenomena. Energy Build. 1999, 29, 141-154. [CrossRef]

15. Ayoob, A.; Talmatamar, T.; Alhabobi, M. Evaluation of some passive cooling techniques for summer comfort. In Proceedings of the European Conference Energy Performance and Indoor Climate in Buildings, Lyon, France, 24-26 November 1994; G. Guarracino, Ecole Nationale des Travaux Publics de l'Etat: Lyon, France, 1994; Volume 2, pp. 463-468.

16. Givoni, B. Effectiveness of mass and night ventilation in lowering the indoor daytime temperatures. Part I: 1993 experimental periods. Energy Build. 1998, 28, 25-32. [CrossRef]

17. Kafescioğlu, R.; Toydemir, N.; Gürdal, E.; Özüer, B. Yapı Malzemesi Olarak Kerpicin Alçı ile Stabilizasyonu. Türkiye Bilimsel ve Teknik Araştırma Kurumu Mühendislik Araştırma Gurubu Proje 1980, 505, 22-30. 
18. Kafescioğlu, R. Çă̆daş Yapı Malzemesi Toprak ve Alker; İTÜ Vakfı Yayınları: İstanbul, Turkey, 2017.

19. Taylor, J.R. An Introduction to Error Analysis: The Study of Uncertainties in Physical Measurements, 2nd ed.; University Science Books: Mill Valley, CA, USA, 1997; pp. 173-179.

20. Kline, S.; McClintock, F. Describing Uncertainties in Single Sample Experiments. Mech. Eng. 1953, 75, 3-8.

21. Orfanidis, S.J. Introduction to Signal Processing; Prentice Hall: Upper Saddle River, NJ, USA, 1996; pp. 427-453.

22. The MathWorks. Signal Processing Toolbox (R2020a); Mathworks: Natick, MA, USA, 2020.

23. Baggs, D.; Mortensen, N. Thermal mass in building design. In Environment Design Guide; Royal Institute of Australian Architects and Australian Council of Building Design Professions Ltd.: Melbourne, Australia, 2006; pp. 1-9.

24. Asan, H. Numerical computation of time lags and decrement factors for different building materials. Build. Environ. 2006, 41, 615-620. [CrossRef]

25. Andreadaki, E. Bioclimatic Design. Environment and Sustainability; University Studio Press: Thessaloniki, Greece, 2006.

(C) 2020 by the authors. Licensee MDPI, Basel, Switzerland. This article is an open access article distributed under the terms and conditions of the Creative Commons Attribution (CC BY) license (http://creativecommons.org/licenses/by/4.0/). 